な會し白工八で國られ米ず損感是はて

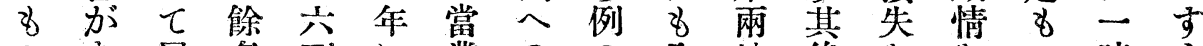
のあ居名百に業のの全地後を基セ時 ら 学名江土於者賣排々の 近、减入豆續行日無何名

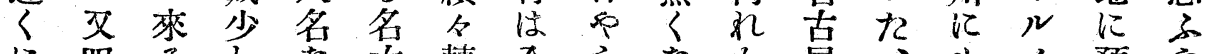

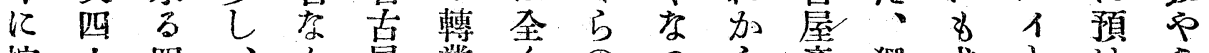

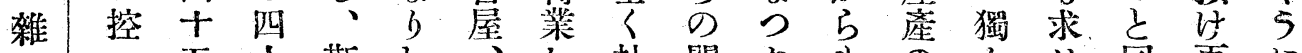

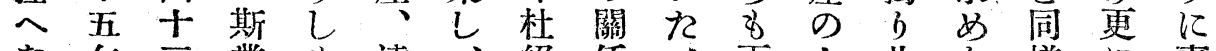
な年三業多遠、縃係、更七此れ樣、賣 分に年はの島職しも尤に赛際結の伊れ らはに全昨雨I前人泩疗に果結國劣

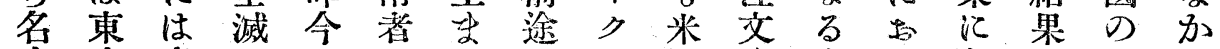

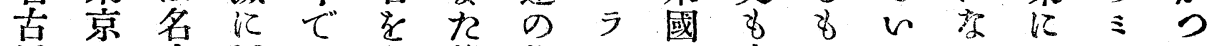

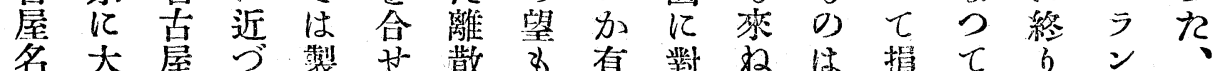

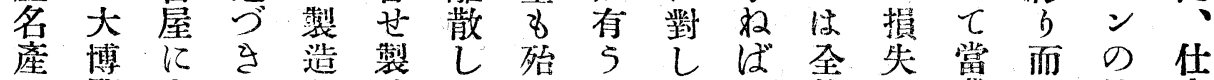

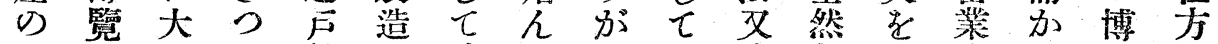
七會名〉數厅彼と鬼は來警招者当覽加

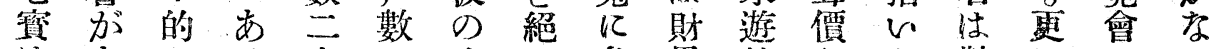

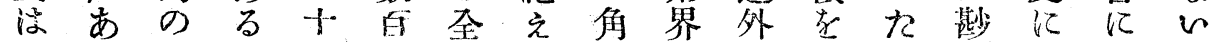
㿽る聯の䟻亲盛れ本の人失の京不出加

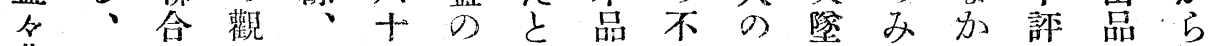

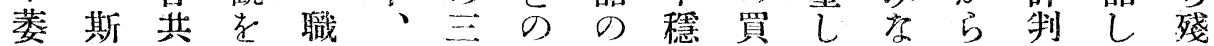

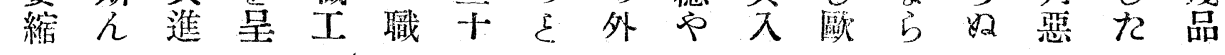

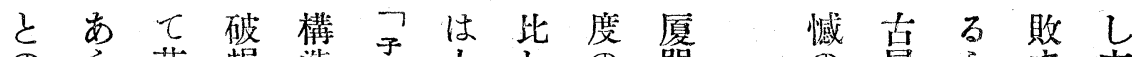

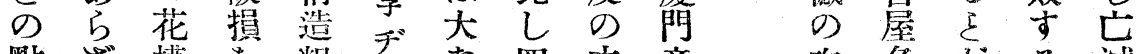

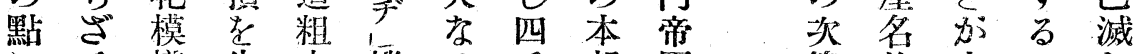
にる樣生末穖る手邦國 第物六はし 於 の等じに械尔弗製領行七つ每つ て $の$ 殊しの點の洋事本市嘪加度了

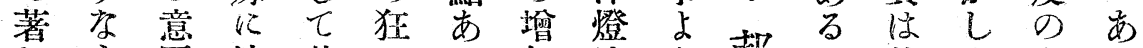

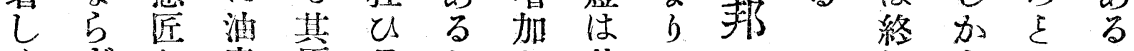

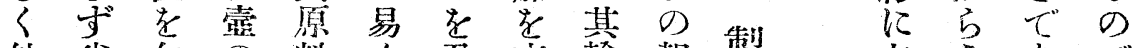

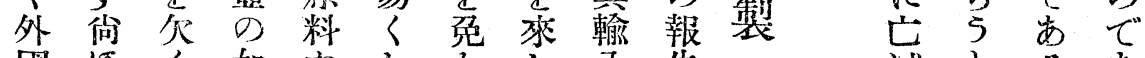

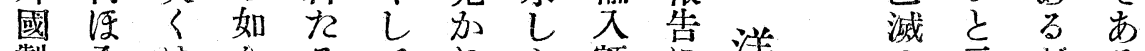
製全は至るてれれ額に洋句云がる

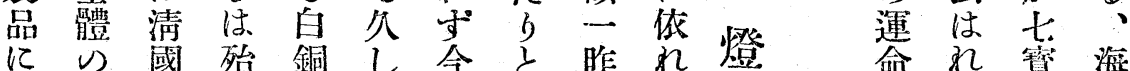

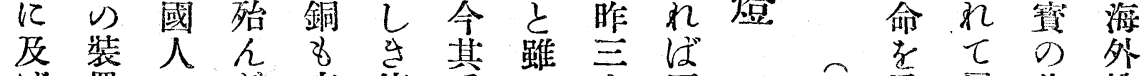

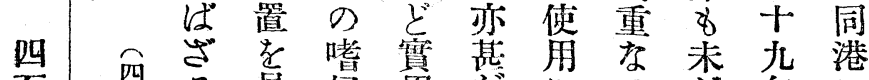

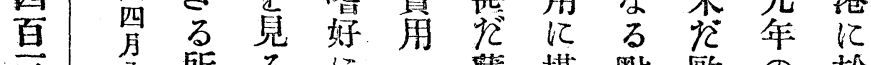

三公所る に

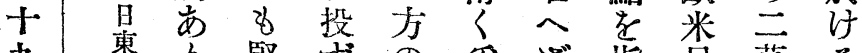

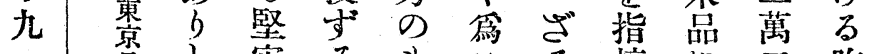
泉牢る る

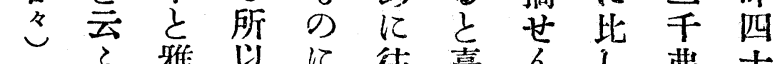
子 雅以《往臺 $几$ 弗十

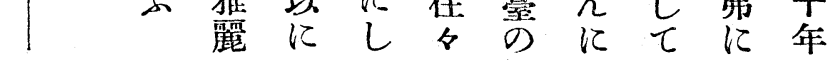

四急居此翰 吾和る。筷出 吾则。敗 品 大 果は 分 烸でし 長 粗 慜市て 製 槊 然に濫 簡 55 回造 架貴名䘖无 


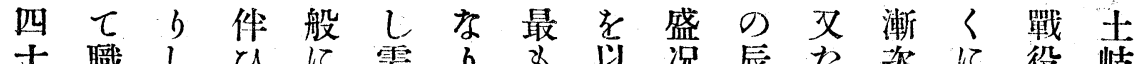

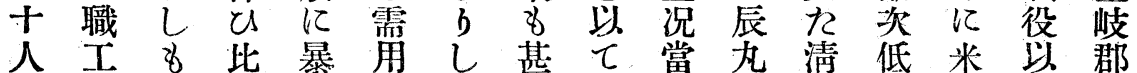

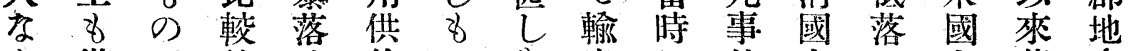
b 從三的世給のき出に件向し 向著方

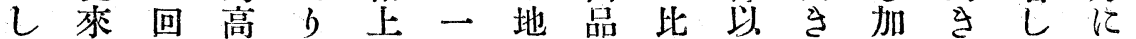

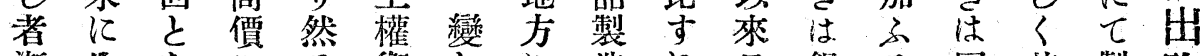
漸比な视衡しに造れ旦銀る同其製

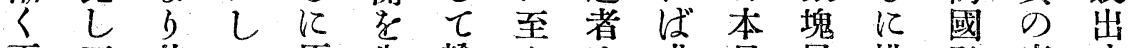
兩三其 $\tau$ 原失輸 b 或品暴排財産守

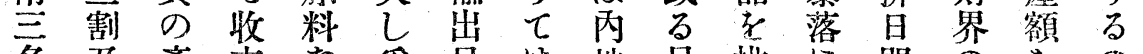

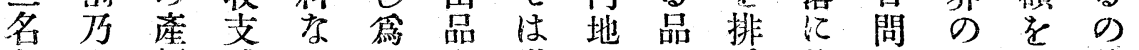

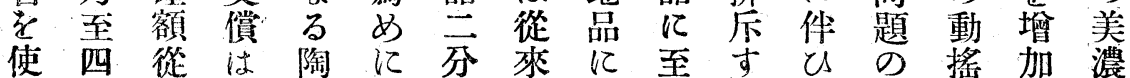
役割來ず士內 、輸轉 b る 愈起にし陶

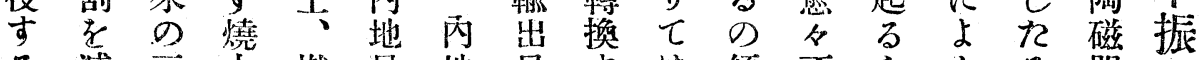
る减三上燃品地品吉は傾不や引当器

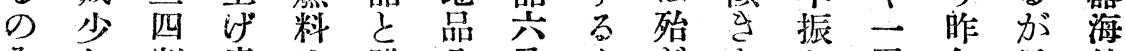

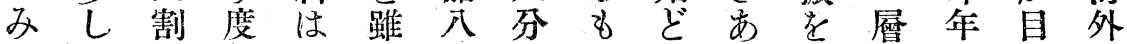
に甚を數物为分、の手b爽の一下輸 $\tau \hbar$ 减 $\cdots$ 價其 の丙續額 $\tau し$ 打月の出

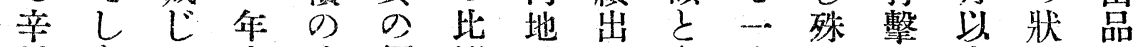

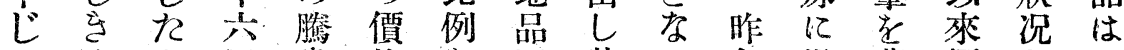

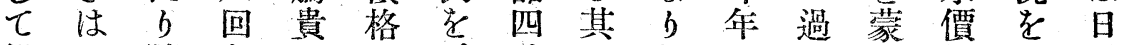
維三隨なに一示分のしの百

職て子く百部の品げ妻難製况金家持

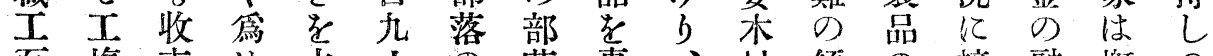
百境支め占十の落專、村傾の接融概つ

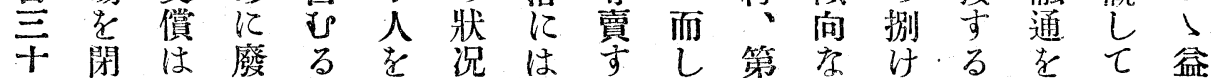

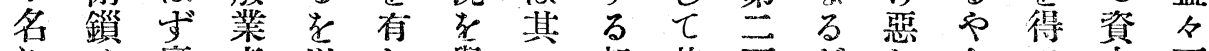

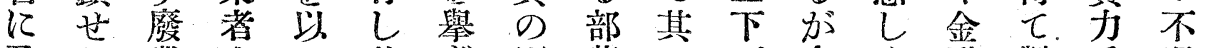
及し業十七其、”影落の石今人融製主况 猪也八其分れ響に輕村其製の造しに

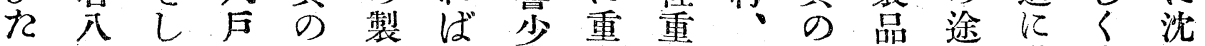

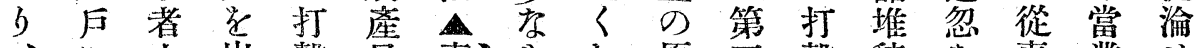

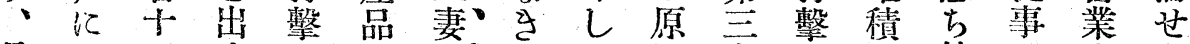

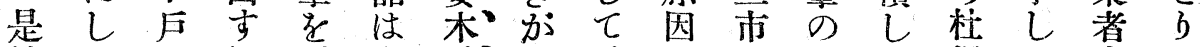
等 $て に$ 受珈村、如品種之重隨絕居中、 は之資至く誹し種名倉なつしれの元

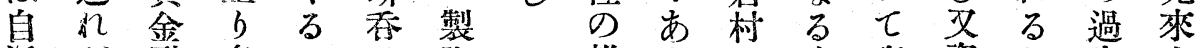

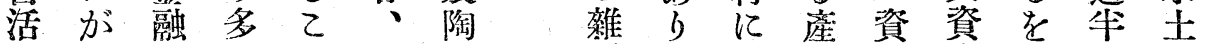

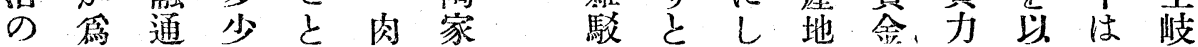
涂めの資亦血約踓七を固あ販郡

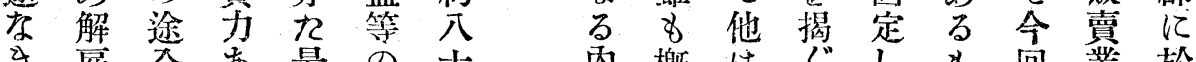
己 㕍全あ最の十丙概はぐし 自業於

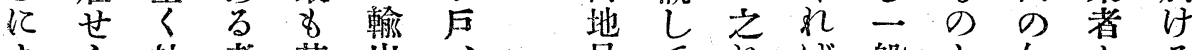

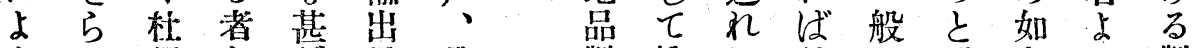

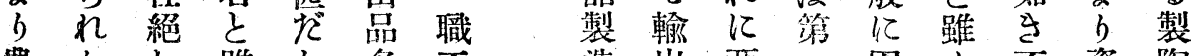
農 L L 踓 $L$ 多工 造出恶一困的不資陶

四

百 四 $+$ 


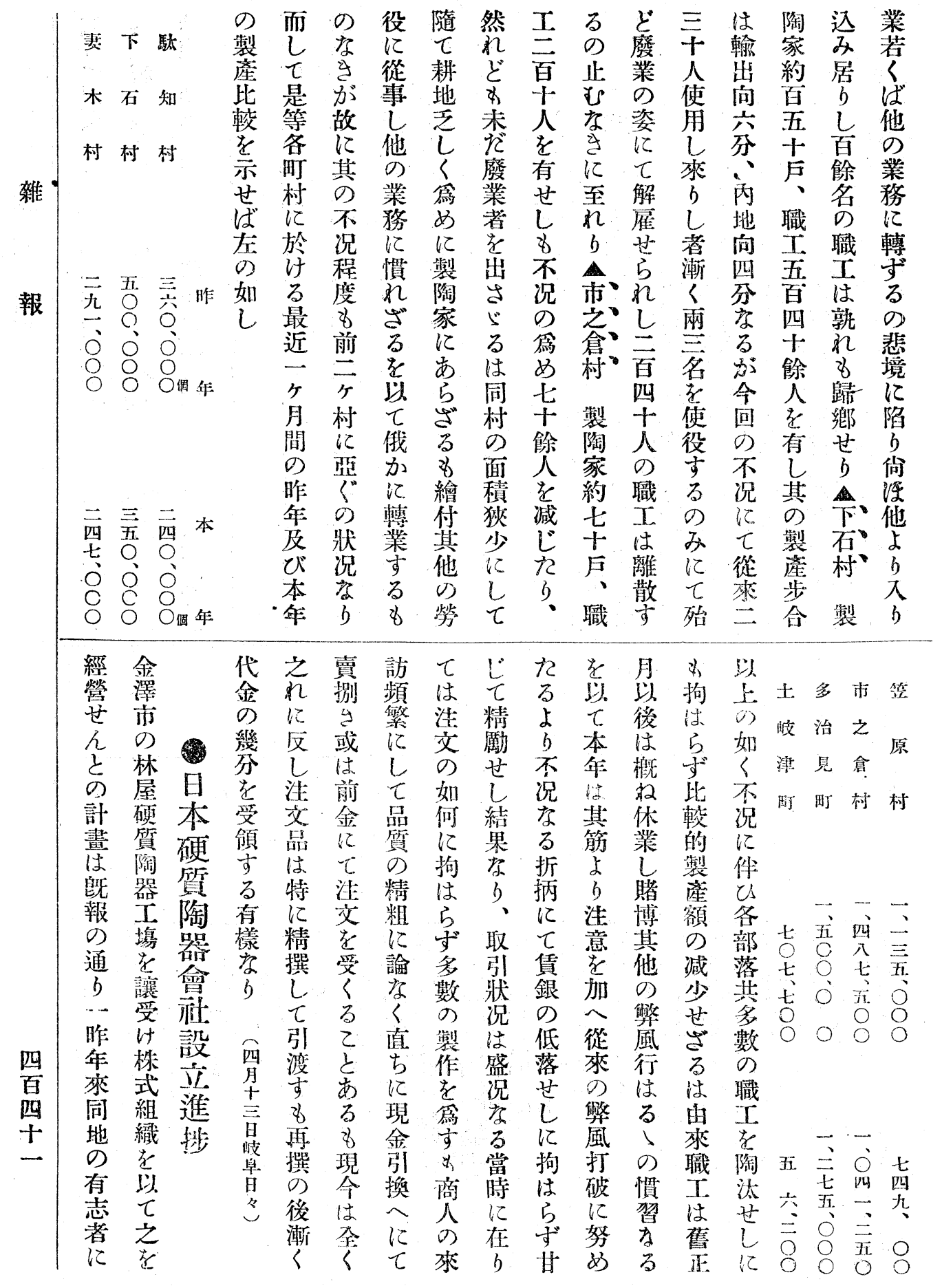




\begin{tabular}{|c|c|c|c|c|c|c|c|c|c|c|}
\hline $\begin{array}{l}\text { 三 } \\
\text { 亲 } \\
\text { 三 }\end{array}$ & 號誥 & & $\frac{1}{3}$ & $\begin{array}{l}\text { 製 } \\
\text { 造 } \\
\text { 沉 } \\
\text { 從 }\end{array}$ & $\begin{array}{l}\text { 中 } \\
\text { な } \\
\text { る } \\
\text { が }\end{array}$ & $\begin{array}{l}\text { 者 } \\
\text { あ } \\
b \\
\tau\end{array}$ & $\begin{array}{l}\text { 川 } \\
\text { 千 } \\
\text { 吉 } \\
\text { 郎 }\end{array}$ & 進 & $\begin{array}{l}\text { 翰 } \\
\text { 旋 } \\
\sigma \\
\text { 結 }\end{array}$ & $\begin{array}{l}\text { 其 } \\
\text { 悪 } \\
\text { 行 } \\
\text { 惱 }\end{array}$ \\
\hline $\begin{array}{l}\text { 互 } \\
\text { 警 } \\
\text { 浩 } \\
\text { 機 } \\
\end{array}$ & $\begin{array}{l}\text { 吅發 } \\
\text { 稱明 }\end{array}$ & 特 & & $\begin{array}{l}\text { j } \\
\text { 万人 }\end{array}$ & 成 & $\begin{array}{l}\text { 早 } \\
8\end{array}$ & 替 & $\begin{array}{l}\text { 式 } \\
\text { 募 } \\
\text { 集 }\end{array}$ & 褁 & 姿 \\
\hline $\begin{array}{l}= \\
f \\
\text { 四 } \\
\text { 日月 }\end{array}$ & $\begin{array}{r}\text { 月公 } \\
\text { 報 } \\
\text { 發 } \\
\text { 日刊 }\end{array}$ & 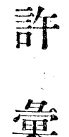 & & $\begin{array}{l}\text { 瑶 } \\
\text { て } \\
\end{array}$ & $\begin{array}{l}\text { は } \\
\text { 其 } \\
\text { 拂 } \\
\text { 込 }\end{array}$ & $\begin{array}{l}\text { 滿 } \\
\text { 株 } \\
\text { に } \\
\text { 洼 }\end{array}$ & $\begin{array}{l}\text { 成 } \\
\frac{6}{6} \\
8 \\
\dot{m}\end{array}$ & $\begin{array}{l}\text { に } \\
\text { 着 } \\
\text { 手 }\end{array}$ & $\begin{array}{l}\text { 金 } \\
\text { 公 } \\
+ \\
\text { 潒 }\end{array}$ & $\underset{6}{b}$ \\
\hline 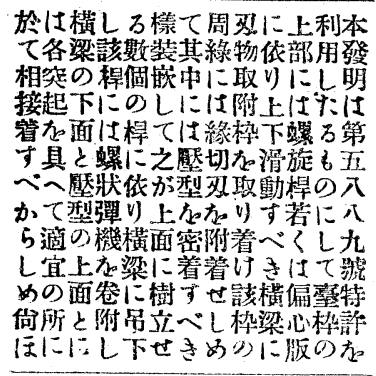 & 要 & 教 & 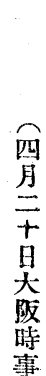 & 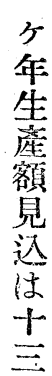 & 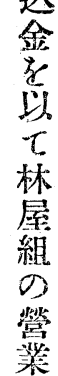 & 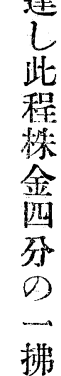 & $\begin{array}{l}\text { D } \\
\text { 其 } \\
\text { 他 } \\
\text { 東 } \\
\text { 京 } \\
\text { 大 } \\
\text { 阪 } \\
\text { に } \\
\text { 於 } \\
\text { て }\end{array}$ & $\begin{array}{l}\text { た } \\
\text { る } \\
\text { に } \\
\text { 幸 } \\
\text { ひ } \\
\text { に } \\
\text { 前 } \\
\text { 田 } \\
\text { 侯 }\end{array}$ & 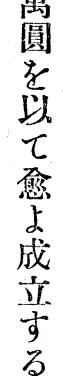 & $\begin{array}{l}\text { 今合 } \\
\text { 窝 } \\
\text { 野 } \\
\text { 㨁 } \\
\text { 道 } \\
\text { 算 } \\
\text { 浦 } \\
\text { 恭 }\end{array}$ \\
\hline 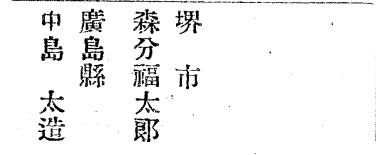 & $\begin{array}{l}\text { 特 } \\
\text { 棓: } \\
\text { 潑 } \\
\text { 主 }\end{array}$ & & 新 & $\begin{array}{l}\text { 萬 } \\
\text { 圓 } \\
\text { 多 } \\
b\end{array}$ & 学 & $\begin{array}{l}\text { 迄 } \\
\text { 起 } \\
\text { 徽 } \\
\text { 收 }\end{array}$ & $\begin{array}{l}\text { 株 } \\
\text { 式 } \\
\text { 引 } \\
\text { 受 }\end{array}$ & $\begin{array}{l}\text { 家 } \\
\text { 早 } \\
\text { 早 }\end{array}$ & 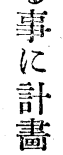 & $\begin{array}{l}\text { 五 } \\
\text { 郎 } \\
\text { 等 }\end{array}$ \\
\hline
\end{tabular}

三
公
五

\begin{tabular}{l} 
造義 \\
法㨘 \\
製 \\
\hline
\end{tabular}

示二

旦月

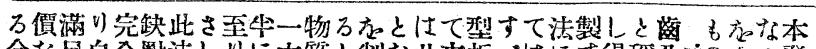

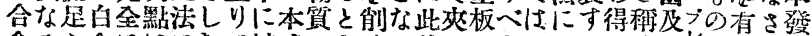
金るな金にはにむて植或ときりる前みにき先化るべす板はすし明

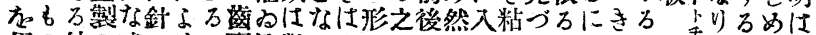

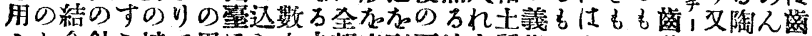

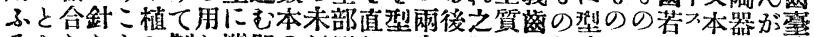

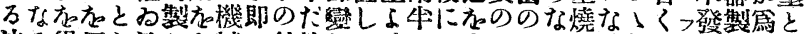

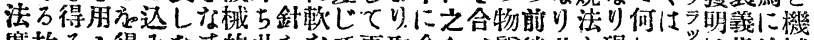

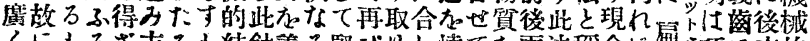

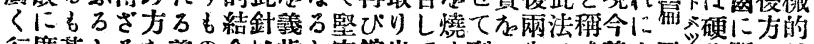

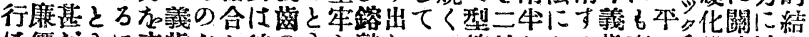

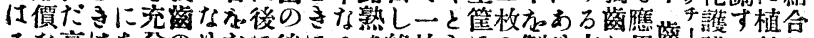

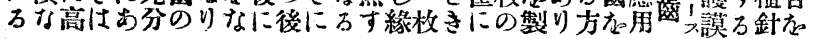

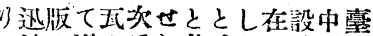
速の滑のにし共すたにけ心秝 に反㩐邊歷めにる万备てにの 他得硬緣型、双處瓦轉之導下 一に固占后後物任製寸心軸部

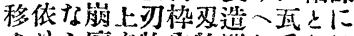

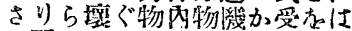
し熨しすべ染にににら版有兩

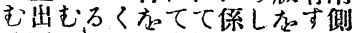
万瓦万こな引充策り屯架摺に と右ととし去各其八し動導

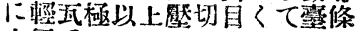
在便受的てり㩁万的な自々と 


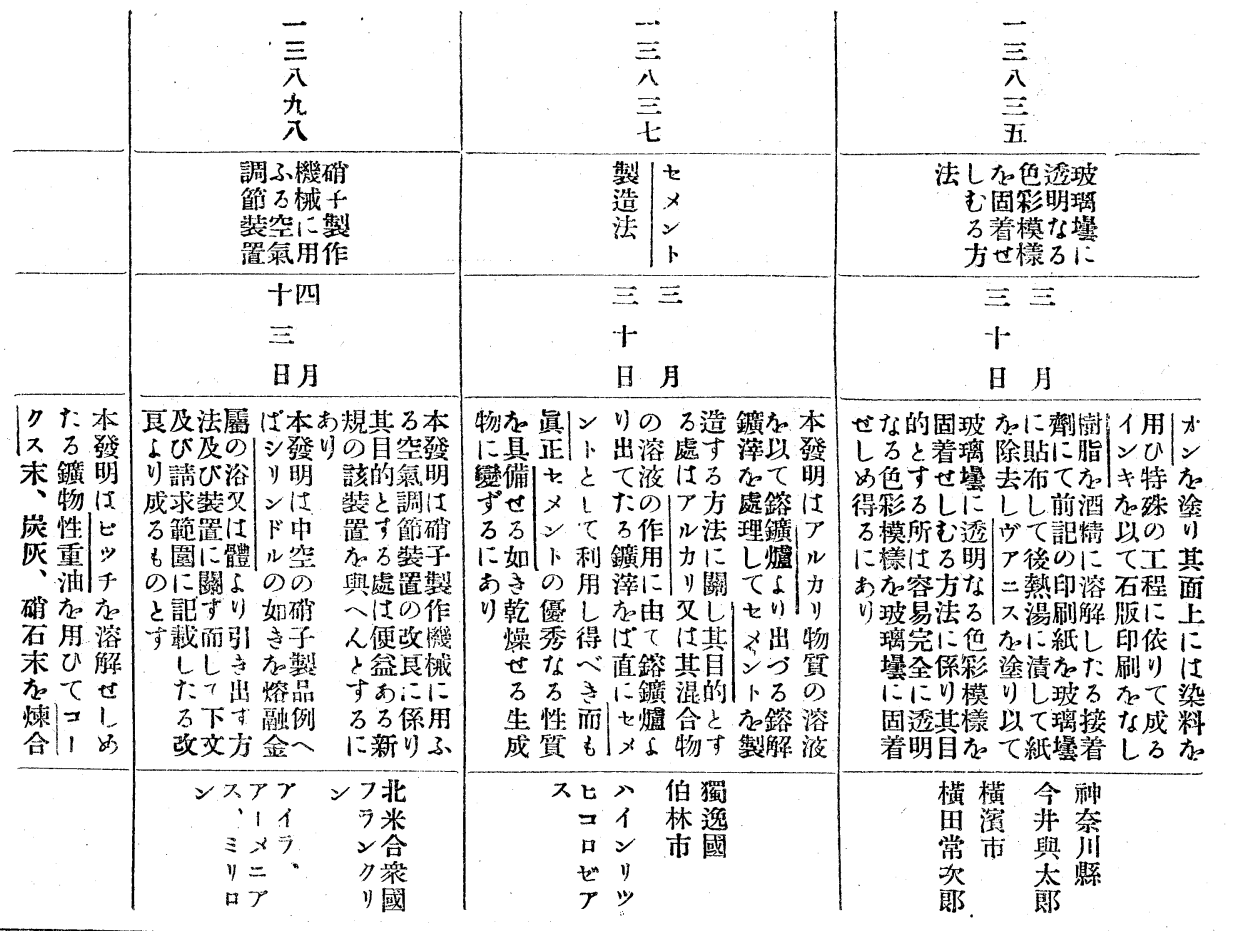

等 b山人れ既 戴同登而宗數れ的 等

同

同

等 級

乙 兵

七 衛

菓 器

子

鉢 物

同同

受

賞 藤

者

は 永

梅 畫

總
總 孝 $\tau$ 勵

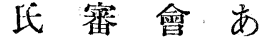

四審香合る

小三清同木五. 賞十査長の如

川水村

文圆六

兵

越

圆

\section{金 名}

八 真

名に

に 總

出

<

齊街

山

本伊

梅

多

重

原

楳

次

山
雇

主左田岩

如 - 氏

出 ᄂ

品
名の吾太
外事五に

十に、於

五は總て

名 錦出 開

克光品加

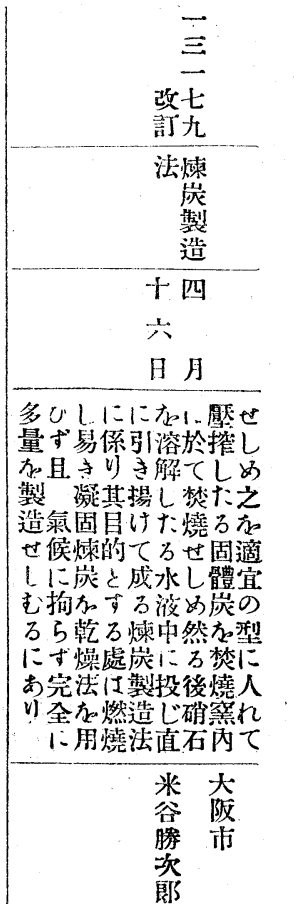

四

百

四

十

四 


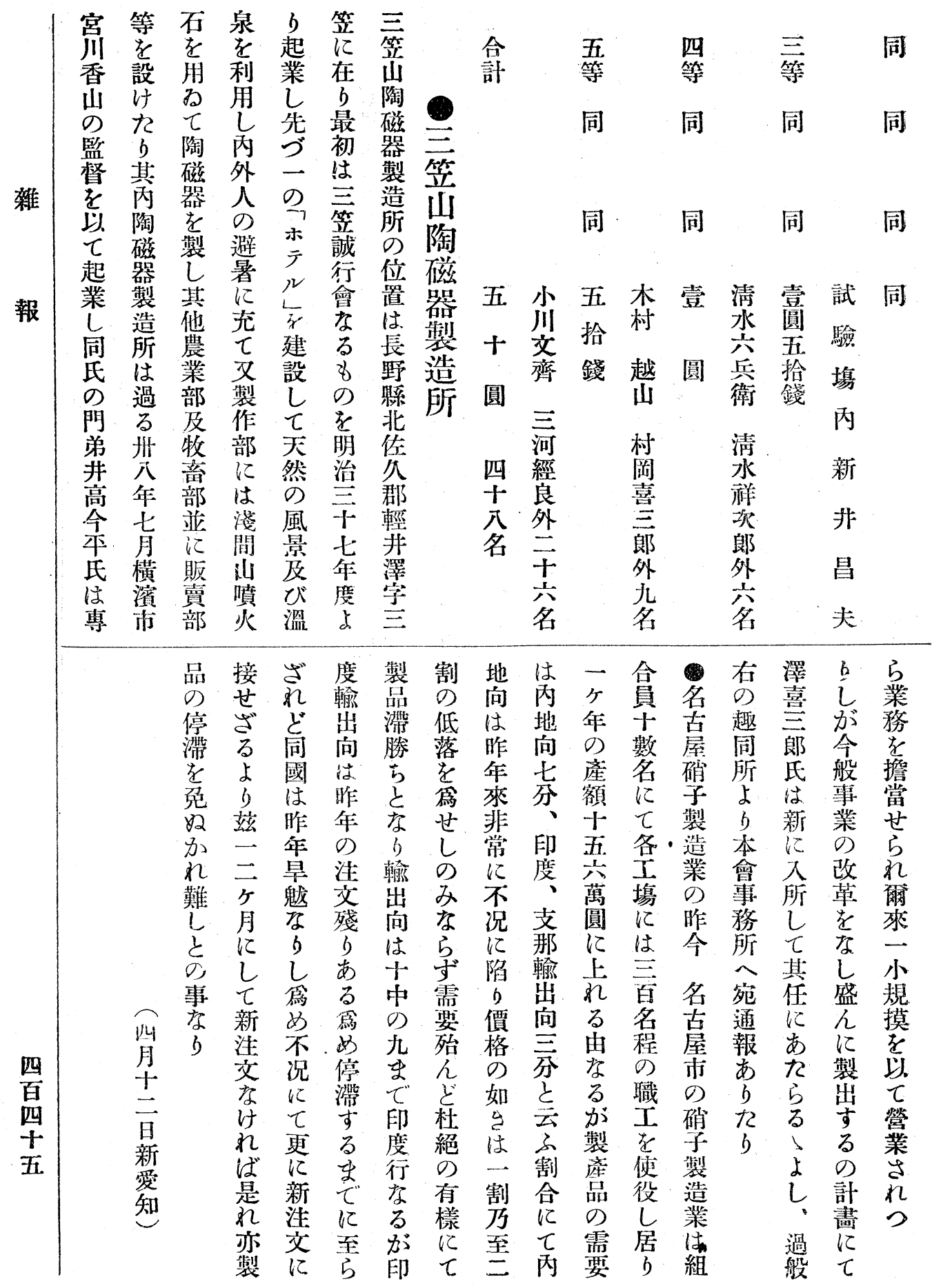

